\title{
A ARTE DE LEONARDO DA VINCI SUBSIDIANDO A CIÊNCIA E O IDEAL DO CUIDADO DE ENFERMAGEM
}

Maria Aparecida de Luca Nascimento* Isabela Jorge de Brito** Marcelo da Silva Dehoul***

\section{Resumo}

Reflexão teórico-filosófica que tem por objetivo demonstrar a arte que precisa ser contemplada durante a execução do procedimento técnico da transferência de soluções para o frasco do microgotas realizada pela equipe de enfermagem, à luz do referencial de Leonardo da Vinci, inspirado em sua obra "O homem vitruviano", para que a harmonia corporal seja mantida, Os autores enfatizaram a relação existente entre a assistência de enfermagem, entendendo-a no seu mais amplo sentido, e o seu próprio lema: "Ciência, Arte e Ideal", Descritores: enfermagem; arte; ciência

\begin{abstract}
Theoretical reflection whose goal is to demonstrate the art a nursing team is required to show in order to perform a technical procedure for transfer of solutions from a normal vial to a microdrops vial, based on Leonardo Da Vinci's theoretical referential, inspired by his work called "Vitruvian Man", so that body harmony is kept. The authors emphasize its relationship to nursing care, viewing it from its broadest sense, and its own motto - "Science, Art and Ideal".

Descriptors: nursing; art; science

Title: The art of Leonardo Da Vinci as a resource to science and the ideal of nursing care
\end{abstract}

\section{Resumen}

Reflexión teórico-filosófica que tiene por objetivo demostrar que se necesita contemplar el arte durante la ejecución dei procedimiento técnico de la transferencia de los excipientes al frasco de microgotas, realizado por el equipo de enfermería, con base al referencial de Leonardo da Vincí, inspirado en su obra "El hombre vítruvíano", para que la armonía corporal se mantenga. Los autores dieron énfasís a la relación que existe con la asístencía de enfermería, entendiéndola en su más amplio sentido, y con su mismo lema: "Ciencia, Arte e Ideal".

Descriptores: enfermería, arte, ciencía

Título: El arte de Leonardo da Vinci para subsídiar la ciêncía y el ideal del cuidado de enfermería

\section{Introdução}

Este estudo surgiu de uma proposta da disciplina Abordagens Metodológicas da Pesquisa em Enfermagem II, ministrada por uma das autoras deste estudo no sétimo período de graduação em enfermagem da Escola de Enfermagem Alfredo Pinto da Universidade do Rio de Janeiro (UNIRIO).

$\mathrm{Na}$ referida disciplina, que se desenvolveu a partir da apresentação de seminários apresentados pelos próprios alunos sob diversos temas, o grupo constituído pelos autores deste estudo abordou aquele relativo às técnicas de enfermagem. Como um dos seus objetivos era o de fomentar a reflexão para a confecção de um artigo a partir do tema sobre o qual o seminário havia se desenvolvido, surgiu um estudo relacionado à forma pela qual a equipe de enfermagem promove a transferência da solução para o equipo de microgotas.

Durante a confecção do artigo supracitado, ao pesquisarmos sobre a anatomia do movimento corporal, uma vez que o objeto de estudo pesquisado relacionava-se à ergonomia, procuramos algum estudo que pudesse nos respaldar. Neste momento, deparamo-nos com o desenho de Leonardo da Vinci, intitulado "O homem vitruviano".

Qual não foi a nossa surpresa ao constatarmos a correlação existente entre um procedimento técnico de enfermagem e toda a arte contida no ato de cuidar, demonstrada através das obras do autor suprareferenciado.

A correlação mencionada diz respeito não só às questões mecânicas, físicas e anatõmicas, como também à subjetividade relacionadas à filosofia e à arte, de um modo geral, e à pintura, em particular.

Deste modo, este estudo relaciona-se à assistência de enfermagem, entendendo-a no seu mais amplo sentido, conforme preconiza o seu lema "Ciência, Arte e Ideal".

\section{Objetivo}

Demonstrar a arte que precisa ser contemplada durante a execução do procedimento técnico da transferência de soluções para o frasco do microgotas, realizada pela equipe de enfermagem, à luz do referencial de Leonardo da Vinci, inspirado em sua obra "O homem vitruviano", para que a harmonia corporal seja mantida.

\section{Tipo de estudo}

Reflexão teórico-filosófico desenvolvida através de levantamento bibliográfico sobre a temática abordada e discutida à luz da arte de Leonardo da Vinci.

\section{$4 \mathrm{~A}$ arte na enfermagem}

Os procedimentos técnicos de enfermagem, através dos quais essa assistência é realizada, sistematizaram-se a partir do século XX nos Estados Unidos, estruturando o seu saber através deles que já àquela época, eram considerados como $\operatorname{arte}^{(1)}$.

Deste modo, a enfermagem incorpora além da reflexão e observação, que são atitudes inerentes à filosofia, a arte que, por definição é o ato de utilizar um "conjunto de preceitos para a perfeita execução de qualquer coisa", "execução prática de uma idéia", ou ainda, "perícia em usar os meios para atingir um resultado"(2)

Com relação ao acima exposto, entendemos que a enfermagem trata-se de uma arte curativa, auxiliando o indivíduo doente ou necessitado de cuidado de saúde(3).

* Professor Adjunto do Departamento de Enfermagem Materno Infantil (DEMI) da Escola de Enfermagem A1fredo Pinto (EEAP) da Universidade do Rio de Janeiro (UNIRIO) - Chefe de Divisão do Departamento de Pós graduação da Pró Reitoria de Pós graduação, Pesquisa e Extensão Doutora em Enfermagem .

** Acadêmicos de Enfermagem do $9^{\circ}$ Período da EEAP - UNIRIO.

E-mail do autor:gemeas@centroin.com.br 
Para falarmos em arte na enfermagem, devemos citar Florence Nightingale que observou que há arte expressa nas ações de enfermagem, considerando todos seus aspectos estéticos, intuitivos e criativos. Com isso, a enfermagem deixou de ser uma rotina mecânica, isenta de qualquer valor humano ou um simples método científico.

Sendo assim, podemos inferir que a implementação do cuidado de enfermagem, através de suas técnicas, vem revestido da essência de quem o promove, diferenciando-o individualmente, mormente se considerarmos este processo como uma relação interpessoal com o objetivo de recuperar ou reabilitar um ser humano.

o ato de cuidar, [ ... ], assume uma dimensão técnica, organizada e sistematizada, porém permeada de subjetividade deixando de ser somente uma ação prática, fria e racional. Desta forma, o cuidar em enfermagem pode ser visualizado como um conjunto de ações técnicas subsidiadas de conhecimento científico e desenvolvidas com arte ${ }^{(4: 24)}$.

\subsection{A história da arte}

A história mostra que a arte data de eras muito remotas, como a pré-cambriana, onde pinturas e monumentos serviam de meio de comunicação e foram deixados como relatos para as gerações futuras. A arte evoluiu muito através dos tempos e então chegarmos ao século $\mathrm{XV}$, marcado pelo renascimento que renovou os estudos em diversos campos de trabalho, como o da ciência e das artes.

À quinze de abril de 1452, em uma pequena aldeia italiana chamada Vinci, nasceu Leonardo. Permaneceu na aldeia até completar dezesseis anos quando foi ser aprendiz de um pintor em Florença. Esta cidade era considerada a capital cultural e Leonardo da Vinci foi cativado pela natureza que o rodeava e passou muito tempo de sua vida tentando entender o mundo da natureza e de todas as suas criaturas.

No estúdio Leonardo aprendeu o ofício de ourives e conheceu as técnicas para fabricar instrumentos musicais e de engenharia elementar, além de uma formação específica em artes como a pintura e escultura. Teve contato também com diversas ferramentas que eram utilizadas para trabalhos como içar, carregar e escavar, que serviram de base para seus inúmeros estudos, idéias e invenções.

Romper com as tradições era uma característica de Leonardo, pois buscava criar um estilo novo voltado para o mundo natural. Utilizou materiais ainda pouco conhecidos como tinta à base de óleo, além de demonstrar sua genialidade e originalidade pintando paisagens como motivo principal das suas obras.

Atualmente reconhece-se que a pintura e a escultura tornaram famoso o aldeão de Vinci, mas suas contribuições científicas fazem parte dos nossos dias de maneira comum, como o helicóptero, o pára-quedas, os estudos sobre ótica, anatomia humana e animal, estudos de botânica, arquitetura, engenharia, física, matemática e filosofia.

Ao pintar um homem debruçado, na "Adoração", Leonardo se preocupou com o detalhe de cada músculo para que pudesse retratar fidedignamente o que via. Para isso ele tinha que entender o corpo humano e só o conseguiu através dos seus estudos sobre anatomia, durante os quais realizou a dissecação de 33 corpos e fez diversos desenhos dos cortes das peças, que são utilizados até hoje.

Em todos os estudos realizados por Leonardo da Vinci aparecem de forma clara o compromisso dele com a ciência, através de cálculos, medições e raciocínios lógicos, porém recheados de arte, sensibilidade e intuição. Leonardo acreditava que existem regras na pintura tal como existem nas leis matemáticas.

Ao estudar a anatomia humana Leonardo da Vinci atribuiu medidas que considerou ideais para um homem tais quais as proporções existentes entre a cabeça e a altura do corpo e das suas partes (membros e tronco). Ainda no mesmo estudo determinou os limites dos movimentos dos membros para que suas funções fossem aproveitadas sem prejuízo para as articulações.

Entre as obras de Leonardo da Vinci, destacamos o desenho "O homem vitruviano", onde o autor mostra especificamente o estudo do ombro humano. Este desenho foi utilizado para que os autores deste estudo pudessem enfatizar a importância da manutenção da postura funcional durante o procedimento técnico da transferência de solução para a bureta do circuito de microgotas, realizado pela equipe de enfermagem, descrita no artigo intitulado "Completando o nível do microgotas - A correlação teórica das ciências exatas com a prática de enfermagem", conforme citação anterior.

\subsection{O homem Vitruviano}

Na obra de Leonardo Da Vinci mostrada, o autor enfatiza quais são os pontos máximos de elevação dos membros para a manutenção da harmonia corporal, corroborando deste modo os aspectos matemáticos, artisticos e científicos que compõem um simples ato componente da assistência de enfermagem.

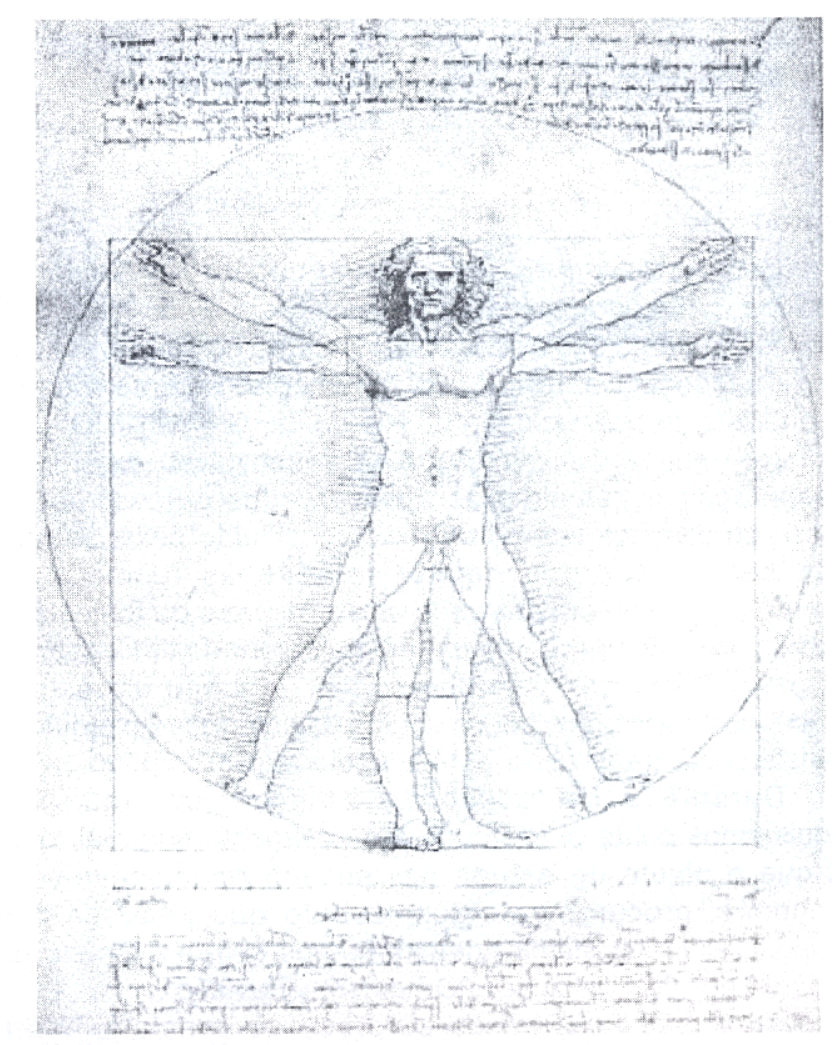

\section{Situando a enfermagem na história da arte}

A enfermagem necessita da ciência em sua prática para fundamentar as técnicas empregadas na assistência, além disso, deve ter espírito pesquisador, sensibilidade e intuição para que o cuidar em enfermagem seja caracterizado como arte. Semelhantemente, Leonardo da Vinci associava, de maneira ímpar, ao seu raciocínio técnico e científico a sensibilidade e o humanismo, que Ihe eram peculiares. Seus estudos sobre os movimentos humanos mostram claramente o trabalho muscular de um ser humano inserido no seu próprio contexto diário; trabalhando, correndo e/ou brincando.

Quando os autores desenvolveram o estudo sobre o microgotas, puderam observar que a arte da enfermagem está em cada procedimento, pois reconhecem que além da racionalidade técnica, $\mathrm{o}$ ato de cuidar requer sensibilidade para 
perceber o paciente e a si mesmo. Segundo Figueiredo o corpo da enfermeira é um dos instrumentos do seu cuidado ${ }^{(3)}$. Neste ponto, vale ressaltar que o cuidado com o corpo de quem cuida é essencial ao ato de cuidar.

Deste modo, demonstramos a partir da obra de Leonardo da Vinci "O homem vitruviano", que a elevação do braço para a realização do procedimento técnico do preenchimento do nível do microgotas, além de inadequada, compromete a articulação escápulo-umeral conforme constatado no estudo dos mesmos autores, já mencionado anteriormente.

No estudo supracitado, o resultado demonstrou que, resumidamente, ao elevar o braço para preencher o nível do microgotas, atitude desnecessária por tratar-se de dois vasos comunicantes, o profissional promoveria um impacto de 15 joules na articulação escápulo-umeral, como resultante da equação $\mathrm{P}=\mathrm{m} \times \mathrm{h}(\mathrm{P}=$ peso; $\mathrm{m}=$ massa; $\mathrm{h}=$ altura $)$ após $\mathrm{a}$ repetição deste procedimento por três vezes.

Sendo assim, ao propormos a realização deste estudo, observamos que, apesar de todo o racionalismo que envolve desde cálculos matemáticos até questões ergonômicas contidas no procedimento técnico em apreço, há que se considerar a subjetividade inerente a este ato não só, porque o corpo de quem cuida é parte integrante do cuidado, como também, porque cuidado é uma relação interpessoal que caracteriza a enfermagem, enf $\sim$ tizando o seu próprio lema: CIÊNCIA, ARTE e IDEAL ${ }^{(3)}$.

\section{Referências}

1. Viteck I. Os caminhos e descaminhos dos procedimentos técnicos de enfermagem [dissertação de Mestrado em Enfermagem]. Rio de Janeiro: Universidade do Rio de Janeiro; 2000. $73 \mathrm{f}$.

2. Nascentes A. Dicionário da língua portuguesa. Rio de Janeiro: Bloch; 1988. 667p.

3. Figueiredo NMA, Carvalho V. O corpo da enfermeira como instrumento do cuidado. Rio de Janeiro: Revinter; 1999. 161 p.

4. Nascimento MAL. A síndrome da criança com o membro superior imobilizado para infusão venosa. Rio de Janeiro: Papel \& Virtual; $2001.155 \mathrm{p}$

Data de Recebimento: 20/03/2003

Data de Aprovação: 22/12/2003 